\title{
AFFORDANCES DAN DAMPAK TEKNOLOGI INFORMASI DAN KOMUNIKASI DI INDUSTRI PARIWISATA (STUDI KASUS TRAVEL AGENT DI SOLO)
}

\author{
Aryati Wuryandari \\ Fakultas Ilmu Komputer, Program Studi Teknik Informatika \\ Universitas Widya Dharma Klaten \\ Email: aryatiwuryandari@unwidha.ac.id
}

\begin{abstract}
ABSTRAK
Dalam perkembangan industri pariwisata, Teknologi Informasi dan Komunikasi (TIK) mempunyai peran penting dalam mengambil peluang. Peluang semakin bertambah besar dengan adanya Internet. Kemudahan yang ditawarkan TIK dengan Internet mengubah cara pelaku industri pariwisata yakni travel agent dalam melakukan bisnis dan mengubah cara wisatawan berinteraksi dengan travel agent. Maraknya media sosial digunakan travel agent untuk mendukung dan meningkatkan interaksi dinamisnya dengan wisatawan. Pengguna TIK di travel agent mempunyai peran yang penting karena memungkinkan apabila berbeda pengguna yang menggunakan TIK maka akan berbeda pula manfaat yang akan diperoleh. Penelitian ini bertujuan memahami lebih lanjut peranan TIK dalam travel agent sebagai salah satu pengembang industri pariwisata dengan pendekatan affordances. Sampling penelitian sebanyak enam travel agent di Solo. Pemilihan sampling menggunakan theorothical sampling. Metode pengumpulan data yaitu wawancara. Data yang digunakan adalah data transkrip hasil wawancara. Metode pengolahan data menggunakan metode grounded theory. Pendekatan analisis data menggunakan pendekatan affordances. Hasil penelitian berupa teridentifikasinya 44 artefak TIK, teridentifikasinya affordance actualization di travel agent sebanyak tujuh item yaitu menjaga keamanan sistem, membangun komunikasi, merencanakan strategi bisnis, membuka pasar, mendukung koordinasi internal, meningkatkan pelayanan dan menjaga integritas sistem. Terindentifikasinya affordance effects di travel agent sebanyak tujuh item yaitu pelayanan yang lebih baik, peningkatan kenyamanan berkomunikasi, pengendalian risiko yang lebih baik, peningkatan visibilitas, penurunan fleksibilitas, penurunan segmen pasar dan penurunan jumlah sanksi. Selain teridentifikasi juga faktor pendukung atau penghambat penggunaan TIK di travel agent sebanyak enam item yaitu sistem penghargaan, dukungan manajemen travel agent, preferensi konsumen, kompatibilitas sistem, bencana alam dan juga keterampilan dan pengetahuan sumber daya manusia.
\end{abstract}

Kata kunci: affordances; teknologi informasi dan komunikasi; travel agent.

\section{ABSTRACT}

In the development of the tourism industry, Information and Communication Technology (ICT) has an important role in taking opportunities. Opportunities are getting bigger with the Internet. The ease that ICTs offer with the Internet changes the way tourism industry players are travel agents in doing business and changing the way tourists interact with travel agents. The rise of social media is used by travel agents to support and enhance its dynamic interaction with tourists. ICT users in travel agents have an important role because it allows if different users use ICTs, the benefits will be different.This study aims to further understand the role of ICT in travel agents as one of the tourism industry developers with an affordances approach. The Sampling of research as many as six travel agents in Solo. The sampling selection uses theoretical sampling. Data collection methods are interviews. The data used is the transcript data from the interview. Data processing methods use the grounded theory method. The data analysis approach uses an affordances approach. The results of the study were an identification of 44 ICT artifacts, identification of affordance actualization in travel agents in seven items, namely maintaining system security, building communication, planning business strategies, opening markets, supporting internal coordination, improving services and maintaining system integrity. Identification of affordance effects in travel agents was identified as many as seven items, namely better service, increased communication convenience, better risk control, increased visibility, decreased flexibility, decreased market segment and decreased a number of sanctions. Besides identified also supporting factors or inhibitors of the use of ICT in travel agents as many as six items, namely the reward system, support management of travel agents, consumer preferences, system compatibility, natural disasters and also skills and knowledge of human resources.

Keywords: affordances; information and communication technology; travel agents. 


\section{PENDAHULUAN}

Industri pariwisata mempunyai potensi dan peluang yang lebih besar dari industri lain [1]dikarenakan banyaknya industri penyedia layanan jasa dan penghasil produk pariwisata yang terkait didalamnya. Dalam perkembangan industri pariwisata, Teknologi Informasi dan Komunikasi (TIK) mempunyai peranan penting dalam mengambil peluang yang ada [2]. Peluang untuk memperluas segmen pasar, menghasilkan produk pariwisata baru, meningkatkan pelayanan dan lain lain. Peluang semakin bertambah besar dengan adanya Internet. Perkembangan TIK yang dialami seiring dengan perkembanan Internet telah mengubah kondisi pasar industri pariwisata menjadi lebih efisien dan efektif [3]. Perubahan kondisi pasar industri pariwisata dikarenakan berbagai kemudahan - kemudahan yang ditawarkan oleh TIK dengan Internet.

Kemudahan yang ditawarkan TIK dengan Internet mengubah cara pelaku industri pariwisata melakukan bisnis serta mengubah cara wisatawan berinteraksi dengan industri pariwisata [3]. Misalnya TIK mengubah cara pelaku industri pariwisata dalam melakukan promosi, yang semula menggunakan brosur saat ini sudah menggunakan website. Sehingga dengan adanya website, memungkinkan wisatawan untuk mengakses informasi secara cepat serta tanpa ada batasan waktu dan tempat. Maraknya media sosial di Internet pun digunakan para pelaku industri pariwisata untuk mendukung dan meningkatkan interaksi dinamis pelaku industri pariwisata dengan wisatawan. Hal ini dilakukan karena banyak keuntungan yang akan didapatkan dari penggunaan media sosial dalam menyampaikan informasi [4]. Selain itu TIK dan Internet juga memiliki potensi untuk meningkatkan pendapatan ekonomi dan sosial dikarenakan TIK bisa mengurangi biaya operasional dan memberikan layanan kepada wisatawan dengan kualitas yang lebih baik.

Kenyamanan yang akan didapatkan dari penggunaan TIK dan Internet berpengaruh pada perilaku wisatawan [1] dan berpengaruh pada perilaku dan cara berfikir pelaku industri pariwisata seperti sikap dan perilaku dalam berkomunikasi. Pengguna TIK mempunyai peranan yang penting dalam hal ini. Pengguna dengan berbagai posisi, berbagai rentang usia, berbagai latar belakang mempunyai pandangan dan pengetahuan yang berbeda tentang TIK dan penggunaanya. Sehingga memungkinkan apabila berbeda pengguna yang menggunakan TIK maka akan berbeda pula manfaat yang akan diperoleh.

Penelitian ini mengambil studi kasus di kota Solo dengan obyek penelitian dalam studi kasus ini adalah travel agent yang berada di kota Solo. Travel agent merupakan salah satu pelaku industri pariwisata yang mempunyai peran penting dalam perkembangan pariwisata. Travel agent membantu dalam identifikasi secara cepat kebutuhan konsumen dan menjangkau konsumen potensial dengan komprehensif dan up-to-date. Namun, perkembangan Internet membawa perubahan struktur industri pariwisata karena memberikan kesempatan pelaku industri pariwisata seperti tempat pariwisata, maskapai penerbangan dan pelaku bisnis perhotelan untuk menjual langsung kepada wisatawan [3]. Akibatnya sebagian besar travel agent merasakan tekanan karena perkembangan tersebut [3].

Pendekatan yang digunakan untuk meneliti dan mengkonfirmasi secara nyata bagaimana TIK digunakan travel agent hingga memberikan manfaat adalah pendekatan affordances. Affordances merupakan pendekatan yang menekankan pada interaksi antara aktor dengan lingkungan [5] dimana lingkungan yang dimaksud adalah lingkungan teknologi yaitu artefak TIK [6]. Sedangkan aktor adalah organisasi yaitu travel agent. Untuk mengeksplorasi lebih dalam, data yang digali dari narasumber akan diidentifikasi dan dikelompokkan ke dalam kerangka proses atau domain area affordances yaitu domain affordances actualization dan affordances effect [7]. Pemahaman yang lebih detail tentang bagaimana TIK digunakan hingga memberikan manfaat bagi travel agent di industri pariwisata dengan pendekatan affordances akan didapatkan antara lain dengan mengkonfirmasi dan mengeksplorasi secara nyata kemungkinan kemungkinan tindakan yang dapat dilakukan travel agent untuk memadukan TIK berdasarkan interaksi antara TIK dengan travel agent, dampak dari interaksi tersebut dan faktor - faktor pendukung atau penghambat penggunaan TIK pada travel agent.

\section{METODOLOGI PENELITIAN}

Pendekatan yang dilakukan dalam penelitian ini adalah pendekatan interpretif dengan metode pengumpulan data menggunakan wawancara. Data yang digunakan adalah data transkrip hasil wawancara. Pemilihan sampling sebanyak 6 travel agent dan 16 informan menggunakan theoretical sampling. Peran posisi informan adalah sebagai Manager/Owner, Administrasi/Akutansi dan Operasional (Ticketing/Tour) seperti pada Tabel 1. 
Tabel 1. Distribusi pembagian peran informan

\begin{tabular}{clc}
\hline No & \multicolumn{1}{c}{ Peran } & Kode Informan \\
\hline 1 & Kepala Cabang A Travel Agent & P1 \\
2 & Manager Operasional B Travel Agent & P2 \\
3 & Owner C Travel Agent & P3 \\
4 & Owner D Travel Agent & P4 \\
5 & Owner E Travel Agent & P5 \\
6 & Owner F Travel Agent & P6 \\
7 & Travel Consultant A Travel Agent & P7 \\
8 & Ticketing B Travel Agent & P8 \\
9 & Ticketing C Travel Agent & P9 \\
10 & Ticketing D Travel Agent & P10 \\
11 & Ticketing E Travel Agent & P12 \\
12 & Ticketing F Travel Agent & P13 \\
13 & Administrasi \& Akuntansi C Travel Agent & P14 \\
14 & Administrasi \& Akuntansi D Travel Agent & P15 \\
15 & Administrasi \& Akuntansi E Travel Agent & P16 \\
16 & Administrasi \& Akuntansi F Travel Agent & \\
\hline
\end{tabular}

Data yang telah terkumpul diinventarisasi dan dilakukan pengolahan data. Tahapan awal dalam melakukan pengolahan data adalah proses mentranskripkan hasil wawancara peneliti dengan informan travel agent. Hasil dari transkrip wawancara kemudian diolah menggunakan strategi sensemaking yakni strategi Grounded theory [8]dan dianalisis menggunakan pendekatan affordances [7]. Interaksi antara organisasi dengan artefak TIK hingga memunculkan tindakan (affordances). Affordances diidentifikasi terlebih dahulu kemudian affordances dikelompokkan ke dalam kerangka proses (domain area affordances) [7]. Domain area affordances dapat dilihat pada Gambar 1.

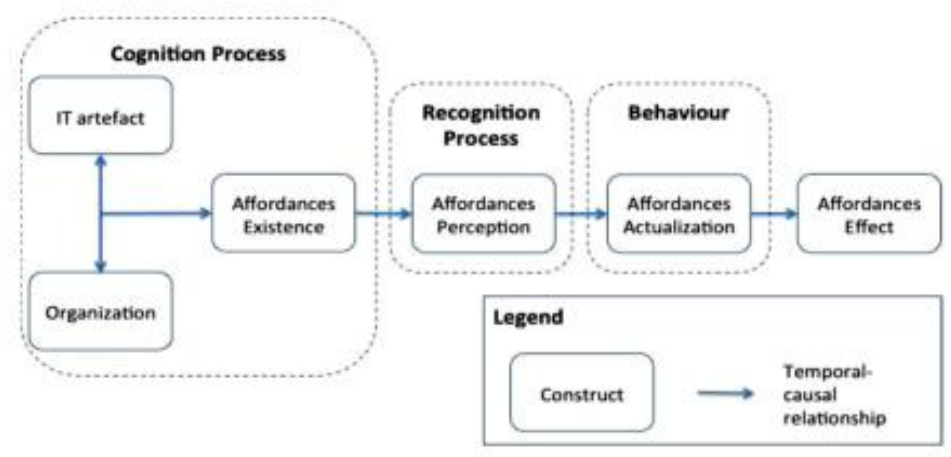

Gambar 1. Domain Area Affordances

Proses analisis data pada Grounded theory berupa pengkodean yaitu open coding dan axial coding. Pada setiap pengkodean dilakukan analisis dengan pendekatan affordances untuk mengidentifikasi keberadaan affordance, affordance actualization dan affordance effects. Domain area affordances mempunyai hubungan kausal untuk setiap kerangka prosesnya. Hubungan kasual antara affordances dalam kerangka proses adalah hubungan antara affordances perception, affordances actualization, faktor pendukung atau penghambat dan affordances effects. Hubungan antara affordances perception, faktor pendukung atau penghambat, affordances actualization serta affordances effects [4] dapat dilihat pada Gambar 2.

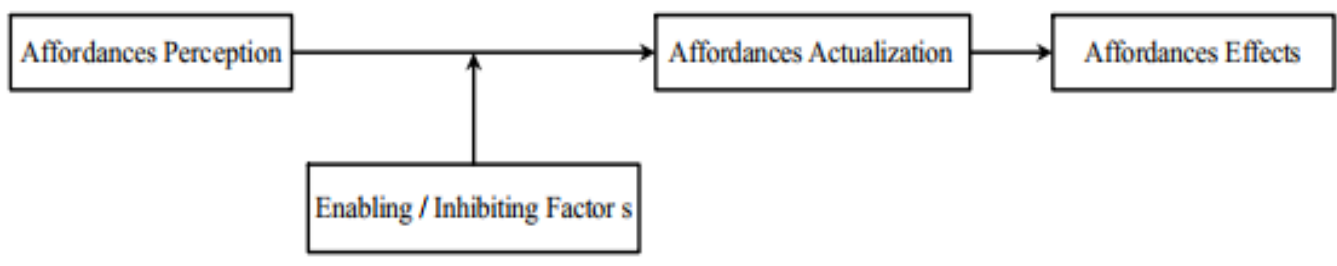

Gambar 2. Hubungan Antara Affordances Perception, Faktor Pendukung Atau Penghambat, Affordances Actualization Serta Affordances Effect 


\subsection{Open Coding}

Tahapan open coding dilakukan pada informan dengan pengklasifikasian berdasarkan peran informan yaitu P1, P2, P3, P4 hingga P16. Dari hasil proses klasifikasi pada P1, P2, P3, P4 hingga P16 kemudian diidentifikasi dan difilter kembali dengan pendekatan affordances untuk mendapatkan final open coding. Hasil dari penyaringan artefak TIK yang digunakan informan teridentifikasi sebanyak 44 artefak TIK. Hasil dari penyaringan affordance actualization yang digunakan informan teridentifikasi sebanyak 41 affordance actualization. Hasil dari penyaringan affordance effects yang digunakan informan teridentifikasi sebanyak 37 affordance effects dan Hasil dari penyaringan faktor pendukung atau penghambat penggunaan TIK di travel agent yang dirasakan informan teridentifikasi sebanyak 52 faktor pendukung atau penghambat.

\subsection{Axial Coding}

Tahapan axial coding pada metode grounded theory dilakukan peneliti dengan mengorganisir dan mengidentifikasi konsep-konsep kunci pada proses analisis seperti identifikasi konsep kunci pada kategori, explorasi kondisi kausal, identifikasi konteks dan kondisi yang mempengaruhi dan mendeskripsikan konsekuensi-konsekuensinya [9]. Axial Coding untuk artefak TIK yang teridentifikasi dari proses open coding ada 4 konsep kunci. Axial Coding yang diidentifikasi pada affordance actualization dari proses open coding ada 7 affordance actualization. Axial Coding yang diidentifikasi pada affordance effects dari proses open coding ada 7 affordance effects dan yang diidentifikasi pada faktor pendukung atau penghambat penggunaan TIK dari proses open coding pada travel agent ada 7 faktor.

\section{HASIL DAN PEMBAHASAN}

\subsection{Artefak TIK}

Artefak TIK merupakan gabungan dari berbagai macam materi dalam suatu produk seperti hardware dan software [10]. Artefak TIK yang ditemukan pada enam travel agent di Solo dan 16 informan yang dijadikan narasumber dalam penelitian ini dikategorikan menjadi empat kategori yaitu Sistem administrasi dan akutansi, Internet, hardware dan jaringan dan alat komunikasi. Artefak TIK yang ditemukan pada travel agent dapat dilihat pada Gambar 3. Untuk sistem administrasi dan akutansi, artefak TIKnya meliputi sistem terintegrasi, sistem akuntasi, sistem akuntansi Jitas, sistem administrasi, Ms Word dan Ms Excell. Untuk Internet, artefak TIKnya meliputi email, chat software (yahoo messenger), social media (facebook dan Instagram) dan website. Untuk website meliputi travel mark website, whole seller website, website maskapai, website hotel, website kereta api dan website travel agent. Untuk hardware dan jaringan, artefak TIKnya meliputi modem, CCTV, LAN, EDC, Token, Printer, Proyektor, Fax, Wifi dan komputer. Untuk artefak TIK yang terakhir yaitu alat komunikasi, artefak TIKnya meliputi telp, handphone non smartphone dan handphone smartphone. Dalam handphone non smartphone artefak TIKnya adalah SMS, sedangkan untuk handphone smartphone artefak TIKnya meliputi BBM (BBM Group), WhatsApp (WhatsApp Call), M-Banking dan SMS. 


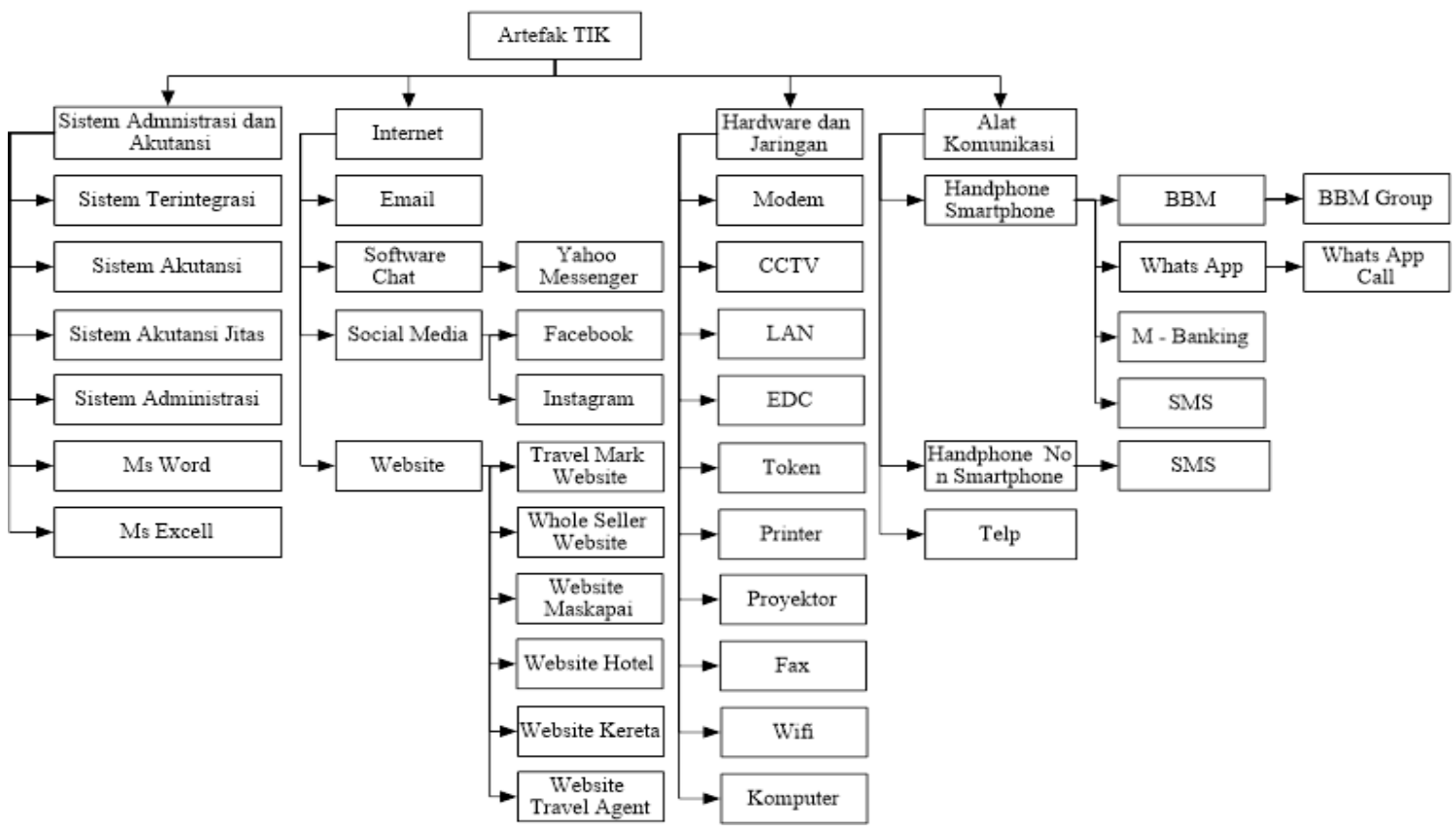

Gambar 3. Artefak TIK Pada Travel Agent

Kategori - kategori pada artefak TIK dalam penggunaanya di travel agent saling terkait satu sama lain atau menjadi suatu kesatuan ketika digunakan. Misalnya transaksi pembayaran bisa dilakukan dengan cash, transfer melalui M-banking atau gesek kartu dengan mesin Electronic Data Capture (EDC) dan ketika sudah selesai kita akan mendapatkan kwitansi yang dicetak dengan menggunakan printer.

\subsection{Affordances}

Artefak TIK yang ditemukan pada travel agent mempunyai potensi yang bisa dimanfaatkan oleh travel agent untuk mencapai tujuannya. Hal ini menyebabkan munculnya interaksi antara travel agent dengan artefak TIK yang disebut dengan affordances. Hubungan interaksi Artefak TIK dengan travel agent (affordances) seperti pada Gambar 4.

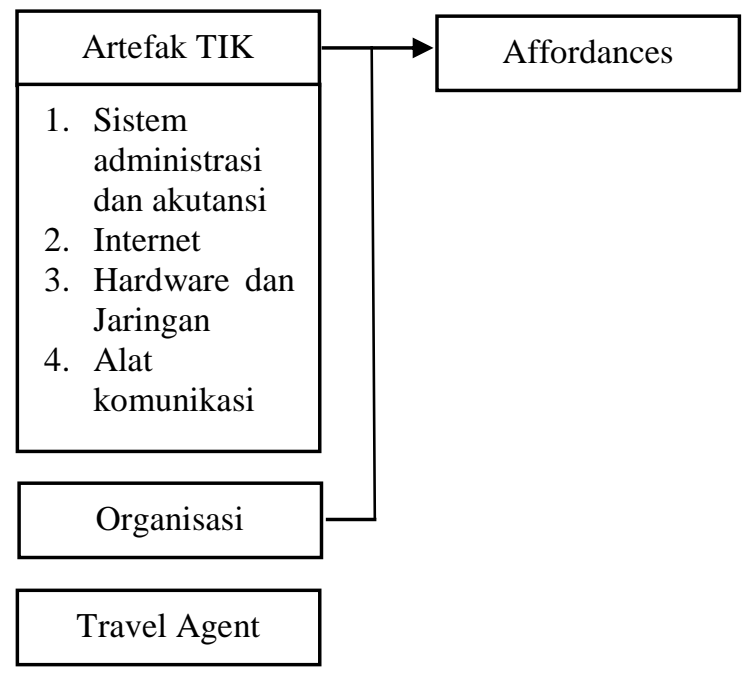

Gambar 4. Hubungan Interaksi Artefak TIK Dengan Travel Agent

Setiap artefak TIK mempunyai affordances yang berbeda beda. Misalnya artefak TIK Ms Excel mempunyai affordances menghitung dan membuat laporan keuangan. Bagi travel agent yang mengetahui affordances dari Ms Excel maka dapat melakukan tindakan (affordances actualization) untuk menggunakan Ms Excel dalam merencanakan strategi bisnis yaitu dengan melakukan perhitung perkiraan harga paket wisata, sebagaimana hasil wawancara berikut : 
"Nggak kalau tour saya ngitung sendiri. Jadi saya punya rumus, tinggal pilih, filenya excel itu, itu nanti shift nya harga berapa ditarik aja, jadi penghitungannya via excel"(P11)

Tetapi tidak setiap travel agent mempunyai kemampuan yang sama dalam memahami affordances Ms Excel. Ada travel agent yang mengetahui affordances Ms Excel untuk membuat laporan keuangan tetapi mereka tidak melakukan tindakan untuk memanfaatkanya karena tidak bisa menggunakanya, sebagaimana hasil wawancara berikut :

"Iya. Kalau ini sengaja saya buat warna-warni kaya gini karena kalau merah ini kita setornya ke agen luar. Kalau yang ini kan nominal tiketnya. Lah kita setornya berapa, dari sini ketahuan profit kita dari luar itu berapa. Iya. Sebenarnya sih yo susah ya Mbak. Yo tapi karena aku nggak bisa excel, dulu sih pernah diajarin cuma karena nggak pernah dipake, jadi lupa "(P14)

\subsubsection{Kemungkinan Tindakan Memadukan TIK dengan Travel Agent}

Setiap artefak TIK mempunyai affordances yang berbeda beda dan setiap travel agent juga mempunyai kemampuan yang berbeda beda dalam memahami potensi tersebut. Dari artefak TIK yang ditemukan dapat diidentifikasi kemungkinan tindakan untuk memadukan TIK dengan travel agent (affordances actualization). Affordances actualization interaksi TIK dengan travel agent yaitu membangun komunikasi, meningkatkan pelayanan, membuka pasar, mendukung koordinasi internal, merencanakan strategi bisnis, menjaga integritas sistem dan menjaga keamanan sistem.

\subsubsection{Dampak Interaksi TIK dengan Travel Agent}

Tindakan yang dilakukan travel agent ketika menggunakan TIK mempunyai potensi menyebabkan suatu dampak atau affordances effects. Dampak yang terjadi akibat tindakan bisa berupa dampak yang diharapkan mau tidak diharapkan. Affordances effects akibat interaksi TIK dengan travel agent yaitu peningkatan kenyamanan berkomunikasi, pelayanan yang lebih baik, pengendalian risiko yang lebih baik, peningkatan visbilitas, peningkatan segmen pasar dan penurunn jumlah sanksi.

\subsubsection{Faktor Pendukung atau Penghambat Penggunaan TIK di Travel Agent}

Dari tindakan yang sudah dilakukan (affordances actualization) oleh travel agent dengan artefak TIK dan dari hasil sebagai akibat dari tindakan (affordances effects) dilakukan analisis dan ditemukan faktor pendukung atau penghambat penggunaan TIK di travel agent. Faktor pendukung atau penghambat penggunaan TIK di travel agent yaitu keterampilan dan pengetahuan sumber daya manusia, preferensi konsumen, dukungan manajemen travel agent, sistem penghargaan, kompatibilitas sistem dan bencana alam.

\subsubsection{Hubungan Kemungkinan Tindakan, Dampak dan Faktor Pendukung atau Penghambat Penggunaan TIK di Travel Agent}

Hubungan dari tindakan yang sudah dilakukan travel agent ketika menggunakan TIK (affordances actualization), dampak sebagai akibat dari tindakan (affordances effects) dan faktor-faktor pendukung atau penghambat penggunaan TIK di travel agent dapat di gambarkan seperti pada Gambar 5.

\begin{tabular}{|c|c|c|}
\hline $\begin{array}{l}\text { Faktor Pendukung atau } \\
\text { Penghambat }\end{array}$ & Affordances Actualization & Affordances Effects \\
\hline $\begin{array}{l}\text { 1. Keterampilan dan } \\
\text { penguasaan sumber } \\
\text { daya manusia } \\
\text { 2. Dukungan manajemen } \\
\text { travel agents } \\
\text { 3. Sistem penghargaan } \\
\text { 4. Kompatibilitas system } \\
\text { 5. Bencana Alam }\end{array}$ & $\begin{array}{l}\text { 1. Membangun } \\
\text { komunikasi } \\
\text { 2. Membuka pasar } \\
\text { 3. Mendukung koordinasi } \\
\text { internal } \\
\text { 4. Meningkatkan } \\
\text { pelayanan } \\
\text { 5. Menjaga keamanan } \\
\text { system } \\
\text { 6. Merencanakan strategi } \\
\text { bisnis }\end{array}$ & $\begin{array}{l}\text { 1. Pelayanan lebih baik } \\
\text { 2. Penambahan segmen } \\
\text { 3. Pengendalian resiko } \\
\text { yang lebih baik } \\
\text { 4. Peningkatan } \\
\text { kenyamana } \\
\text { berkomunikasi } \\
\text { 5. Peningkatan visibilitas } \\
\text { 6. Penurunan jumlah } \\
\text { sanksi }\end{array}$ \\
\hline
\end{tabular}

Gambar 5. Hubungan Affordances Actualization, Affordances Effects Dan Faktor Pendukung Atau Penghambat Penggunaan TIK Di Travel Agent 
Tindakan yang mungkin dilakukan travel agent atau affordances actualization mempunyai hubungan kausal atau sebab akibat dengan dampak dari tindakan atau affordances effects. Misalnya affordances actualization "membangun komunikasi" dilakukan akan mempunyai dampak peningkatan kenyamanan berkomunikasi dan pelayanan yang lebih baik. Begitupun sebaliknya "kenyamanan berkomunikasi" dan "pelayanan yang lebih baik" bisa muncul dikarenakan tindakan travel agent dalam membangun komunikasi.

Dari hubungan kausal antara affordances actualization dan affordances effects dapat dianalisis dan ditemukan faktor pendukung atau penghambat penggunaan TIK. Faktor pendukung atau penghambat juga mempunyai hubungan kausal dengan affordanes actualization. Misalnya faktor pendukung dan penghambatnya yaitu keterampilan dan pengetahuan sumber daya manusia berpengaruh munculnya tindakan membangun komunikasi. Keterampilan dan pengetahuan sumber daya manusia yang dimiliki setiap orang berbeda beda sehingga akan mengakibatkan munculnya tindakan membangun komunikasi yang berbeda beda pula. Hal ini tergantung dari keterampilan dan pengetahuan yang dimilki manusianya dalam memahami potensi artefak TIK. Selain mempunyai hubungan kausal, faktor pendukung atau penghambat juga menjadi pengait yang mengkaitkan affordances actualization dengan affordances effects. Misalnya faktor pendukung atau penghambat keterampilan dan pengetahuan sumber daya manusia mempunyai hubungan kausal dengan peningkatan kenyamanan berkomunikasi. Peningkatan kenyamanan berkomunikasi akan didapatkan oleh travel agent atau wisatawan ketika travel agent paham benar bagaimana cara nya membangun komunikasi. Untuk memahami cara membangun komunikasi tergantung dari keterampilan dan pengetahuan sumber daya manusianya. Keterampilan dan pengetahuan sumber daya manusia yang berbeda akan berakibat terhadap tindakan membangun komunikasi dan tingkat kenyamanan berkomunikasi yang didapatkan.

\section{KESIMPULAN}

TIK digunakan hingga memberikan manfaat bagi travel agent di industri pariwisata Solo dengan pendekatan affordances yaitu travel agent di Solo mayoritas sudah memanfaatkan TIK dan Internet dalam kegiatan operasionalnya dikarenakan berbagai kemudahan yang ditawarkan oleh TIK dan Internet.Tetapi masih ada beberapa travel agent yang masih menerapkan sistem manual dalam operasionalnya. Misalnya dalam mengelola administrasi dan keuangannya masih ada beberapa travel agent yang belum bisa memanfaatkan TIK lebih memilih menggunakan cara konvensional karena merasa nyaman yakni ditulis dibuku.

Kemungkinan kemungkinan tindakan yang dilakukan untuk memadukan TIK berdasarkan interaksi antara TIK dengan travel agent yaitu membangun komunikasi, meningkatkan pelayanan, mendukung koordinasi internal, membuka pasar, merencanakan strategi bisnis, menjaga integritas sistem dan menjaga keamanan sistem. Dampak dari tindakan terkait dengan interaksi TIK dengan travel agent yaitu peningkatan kenyamanan berkomunikasi, pelayanan yang lebih baik, peningkatan visibilitas, pengendalian risiko yang lebih baik, peningkatan segmen pasar dan penurunan jumlah sanksi. Faktorfaktor yang mendukung atau menghambat penggunaan TIK di travel agent yaitu keterampilan dan pengetahuan sumber daya manusia, dukungan manajemen travel agent, sistem penghargaan, preferensi konsumen, kompatibilitas sistem dan bencana alam.

\section{DAFTAR PUSTAKA}

[1] D. Buhalis and R. Law, "Progress In Information Technology And Tourism Management: 20 Years On And 10 Years After The Internet-The State Of Etourism Research,” Tour. Manag., vol. 29, no. 4, pp. 609-623, 2008.

[2] C. Petti and G. Passiante, "Getting The Benefits Of ICTs In Tourism Destinations: Models , Strategies and Tools," pp. 1-12, 2008.

[3] J. X. Ma, D. Buhalis, and H. Song, “Icts And Internet Adoption In China's Tourism Industry," Int. J. Inf. Manage., vol. 23, no. 6, pp. 451-467, 2003.

[4] F. Wahid and Ø. Sæbø, "Affordances And Effects Of Promoting Eparticipation Through Social Media," in Lecture Notes in Computer Science (including subseries Lecture Notes in Artificial Intelligence and Lecture Notes in Bioinformatics), 2015, vol. 9249, pp. 3-14.

[5] J. J. Gibson, "Gibson Theory of Affordances.pdf," Chapter Eight The Theory of Affordances. pp. 127-136, 1986.

[6] I. Hutchby, “Technologies, Texts And Affordances," Sociology, vol. 35, no. 2, pp. 441-456, 2001.

[7] G. Pozzi, F. Pigni, and C. Vitari, "Affordance Theory in the IS Discipline: a Review and Synthesis of the Literature," Twent. Am. Conf. Inf. Syst. Savannah, 2014, vol. 13, pp. 1-12, 2014.

[8] N. K. Denzin and Y. S. Lincoln, "The Sage Handbook of Qualitative Research, 2nd ed. Edited by Norman K. Denzin, and Yvonna S. Lincoln," Library (Lond)., vol. 28, no. August, pp. 467-468, 
Jurnal SIMETRIS, Vol. 9 No. 2 November 2018

P-ISSN: 2252-4983, E-ISSN: 2549-3108

2006.

[9] J. Creswell, Research Design : Pendekatan Kualitatif, Kuantitatif, dan MIxed. 2013.

[10] W. J. Orlikowski and S. R. Barley, "Technology And Institutions: What Can Research On Information Technology And Research On Organizations Learn From Each Other? Orlikowski \& Barley/Technology \& Institutions," MIS Q., vol. 25, no. 2, pp. 145-165, 2001. 